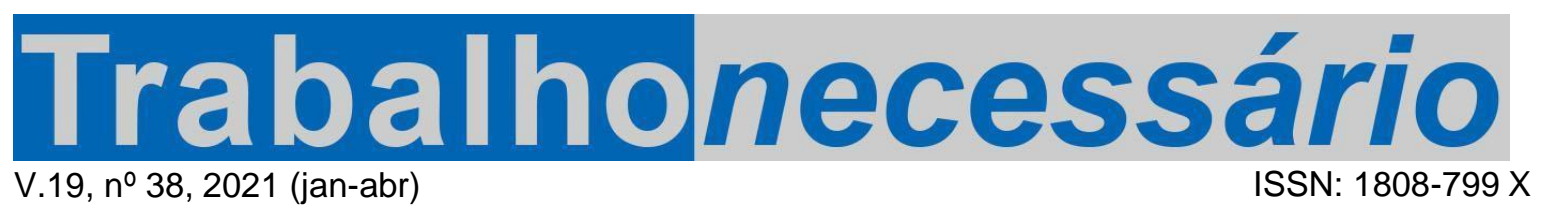

\title{
GRUPO INTELECTUAIS NEGRAS UFRJ: A INVENÇÃO DE UMA COMUNIDADE CIENTÍFICA E SEUS DESAFIOS 1
}

\author{
Giovana Xavier²
}

\begin{abstract}
Resumo
Meu objetivo com este texto é discutir avanços e dificuldades da invenção de uma comunidade científica fundamentada na tradição feminista negra de articular pensar e fazer. Alicerçada em conceitos como autodefinição (COLLINS, 2019) e narrativa na primeira pessoa (XAVIER, 2019) analiso os diversos significados do Grupo de Estudos e Pesquisas Intelectuais Negras na UFRJ. Com isso, menos do que rebater pressupostos de objetificação da estrutura acadêmica, interessa-me apresentar caminhos alternativos de produção científica, dentro da abordagem que conceituo história intelectual das mulheres negras.
\end{abstract}

Palavras-chave: história intelectual de mulheres negras; narrativa na primeira pessoa; validação de conhecimento.

\section{INTELECTUALES NEGRAS UFRJ: LA INVENCIÓN DE UNA COMUNIDAD CIENTÍFICA Y SUS DESAFÍOS}

\section{Resumen}

Mi objetivo con este texto es discutir los progresos y las dificultades de la invención de una comunidad científica basada en la tradición feminista negra de articular el modo de pensar y hacer. Basado en conceptos como autodefinición (COLLINS, 2019) y narrativa en primera persona (XAVIER, 2019), analizo los diferentes significados del Grupo de Investigación e Estudios Intelectuales Negras de la UFRJ. Por lo tanto, menos que refutar los supuestos de la objetivación de la estructura académica, me interesa presentar caminos alternativos de producción científica, dentro del enfoque que conceptualizo la historia intelectual de las mujeres negras.

Palabras clave: negras intelectuales; narrativa en primera persona; validación de conocimientos.

\section{BLACK FEMALE INTELLECTUALS GROUP UFRJ: THE INVENTION OF A SCIENTIFIC COMMUNITY AND ITS CHALLENGES}

\begin{abstract}
My aim with this text is to discuss advances and difficulties of the invention of a scientific community based on the black feminist tradition of articulating thinking and doing. Based on concepts such as self-definition (COLLINS, 2019) and first-person narrative (XAVIER, 2019) I analyze the different meanings of the Black Women Intellectuals Studies and Research Group at UFRJ. Thus, rather than rebutting the assumptions of objectification of the academic structure, I am interested in presenting alternative paths of scientific production, within the approach that I
\end{abstract} conceptualize the intellectual history of black women.

Key-Worlds: Black Females Intellectual; History; First person narrative; Validation of Knowledge.

\footnotetext{
${ }^{1}$ Artigo recebido em 17/06/2020. Primeira avaliação em 18/08/2020. Segunda avaliação em 19/08/2020. Aprovado em 01/09/2020. Publicado em 25/02/2020. DOI: https://doi.org/10.22409/tn.v19i38.43121.

2 Doutora em História Social pela Universidade Estadual de Campinas - Unicamp, Campinas - São Paulo, Brasil. Profa. Didática e Prática de Ensino de História Faculdade de Educação da Universidade Federal do Rio de Janeiro - UFRJ, Rio de Janeiro - Brasil. Líder apoiada pelo Programa de Aceleração e Desenvolvimento de Lideranças Femininas Negras Marielle Franco do Baobá Fundo para Equidade Racial. Email: contatogiovanaxavier@gmail.com. ORCID: 0000-0002-6118-3889.

Lattes: http://lattes.cnpq.br/9883445785268500
} 
Percebi que minha formação como cientista social era inadequada para a tarefa de estudar o conhecimento subjugado do ponto de vista das mulheres negras. Isso porque os grupos subordinados perceberam há muito tempo que é necessário recorrer a formas alternativas para criar autodefinições e autoavaliações independentes, rearticulando-as por meio de nossos próprios especialistas. Como outros grupos subordinados, as afro-americanas não apenas desenvolveram um ponto de vista específico das mulheres negras, mas usaram formas alternativas de produzir e validar o conhecimento para isso.

(PATRICIA HILL COLLINS, 2019, p. 402)

Hoje, eu gostaria de pedir que todo mundo fechasse os olhos e se perguntasse "como eu quero contar minha história?" Imagine-a. Na forma de um desenho. De um poema. Um livro. Uma música. Do jeito que você quiser. Afinal, ela é sua. Só sua. De mais ninguém.

(GIOVANA XAVIER, 2019) ${ }^{3}$

\section{Como você quer contar sua história?}

Esta é uma história de muitos começos. Oito de abril de 1979, dia do meu nascimento, em tarde de céu azul e sol escaldante, no subúrbio carioca do Irajá, como cresci ouvindo minha mãe, com sorrisos e olhos marejados, contar-me. Março de 1999, ano em que vivi minha primeira grande mudança. De jovem suburbana, trabalhadora informal, me transformo em estudante universitária do curso de História da UFRJ. Janeiro de 2009, um ano depois de enterrar minha mãe e minha avó, desembarquei nos EUA. País no qual por durante um ano vivi a experiência de ser estudante internacional na New York University. ${ }^{4}$ Março de 2012, depois de longo ritual, deixo, acompanhada por amigos e familiares, o prédio do Instituto de Filosofia e Ciências

\footnotetext{
${ }^{3}$ Meu trabalho de intelectual pública envolve a redação de textos livres para diálogo com o público aos quais denomino narrativas na primeira pessoa. É o caso de Como você quer contar sua história?, preparado e lido no lançamento do meu livro Você pode substituir Mulheres Negras como objeto de estudo por Mulheres Negras contando sua própria história, na XVII Festa Literária Internacional de Paraty, 2019.

${ }^{4}$ Doutorado Sandwich CNPq, realizado no Departamento de História da NYU, onde tive a oportunidade marcante de ter como supervisora a Profa. Dra. Barbara Weinsten.
} 
Humanas da Unicamp. Com céu estrelado, carregava em meu ventre um bebê de cinco meses. Na bolsa, um diploma de doutorado. ${ }^{5}$ Outubro de 2013, céu azul e sol escaldante voltaram. Com Peri no colo, agarrado ao meu peito, após assinar um documento, tomava posse de um dos lugares mais importantes da minha vida: o de professora adjunta da Universidade Federal do Rio de Janeiro, sonhado e planejado por meus ancestrais.

Sete anos mais tarde, atendendo ao convite da Revista Trabalho Necessário, eu estou aqui. Iniciando na primeira pessoa as reflexões por escrito de minha carreira, marcada pelo grande feito de construir um projeto de formação e produção científicas inédito no Brasil, pois focado na que conceituo história intelectual das mulheres negras. Uma nova abordagem que desenvolvo dentro do campo do ativismo científico (XAVIER; MATTOS, 2016). Fundamentada em paradigmas da história social, do feminismo negro e da educação transgressora, tal abordagem tem me permitido avançar no estudo das formas de agir, pensar e produzir saberes empreendidas por mulheres negras em tempos e espaços distintos (hooks, 2013).

Composto de muitas cenas e ritos variados - solitárias leituras, traduções, escrita de artigos, colunas, projetos; salas de aula e redes sociais repletas de vidas e desejos de escrever novas histórias; litígios acadêmicos sobre quem tem o direito à fala acadêmica - este projeto transformou minhas concepções sobre produção do conhecimento científico. Uma transformação que me impulsiona a, como professora universitária, forjar e praticar uma "epistemologia alternativa" aos pressupostos de objetificação e inferioridade feminina negra (COLLINS, 2019). Compartilhados pela comunidade científica, tais pressupostos culminam na subrepresentatividade de mulheres negras não somente em programas de pós-graduação, mas em comitês científicos de áreas, conselhos editoriais de periódicos e no mercado editorial universitário (SILVA, 2010; XAVIER, 2018).

Atravessada por muitos afetos, nas páginas que se seguem, transito livremente por histórias de apagamentos, conflitos, dores (SANTANA, 2020). Assuntos que nos meus percursos acadêmicos como intelectual negra misturam-se a muitas alegrias e

\footnotetext{
${ }^{5}$ Em 14/03/2012 defendi a tese Brancas de almas negras? Beleza, racialização e cosmética na imprensa negra pós-emancipação (EUA, 1890-1930), orientada pelo Prof. Dr. Sidney Chalhoub no Programa de Pós-Graduação em História Social da Unicamp.
} 
conquistas geradas na universidade pública, e, importantíssimo dizer, também fora dela. Por isso, reforçando o compromisso assumido com minha comunidade, como teórica e ativista, registro profunda gratidão às milhões de mulheres negras brasileiras. Sujeitas políticas que inspiram e contribuem para a sustentação de meu trabalho, ensinando-me, com pontos de vista riquíssimos, conceitos, métodos e paradigmas sobre educação, letramento, gestão orçamentária, planejamento familiar, espiritualidade. Entre tantos outros assuntos que entram pela porta da frente da UFRJ, trazidos por filhas, sobrinhas e netas.

Como primeiras da família a cursar a universidade pública, estas jovens me impulsionam a traduzir para o discurso científico nossos trajetos intelectuais. Obrigada por me contarem suas histórias! Espero que este artigo represente uma fonte de recursos e ideias para produção de conhecimentos centrados nas insubmissas premissas de mulheres negras (EVARISTO, 2011).

\section{Intelectuais negras UFRJ: inventando uma comunidade científica}

Em maio de 2015, apresentei ao colegiado do Departamento de Didática da Faculdade de Educação da UFRJ a proposta do curso Intelectuais Negras: escritas de si, saberes transgressores e práticas educativas de mulheres negras. Aprovada por unanimidade, a proposição passou a integrar a grade curricular de disciplinas eletivas do curso de Pedagogia, aberta a todos os estudantes da UFRJ e demais universidades brasileiras e internacionais. ${ }^{6}$

Fundamentado nas articulações horizontais entre saberes ativistas, acadêmicos e pessoais, o referido Grupo possui um programa formativo amplo e diversificado, que oportuniza tanto a formação de novas gerações acadêmicas quanto a produção de teorias, conceitos, práticas educativas e métodos focados na referida história intelectual de mulheres negras ${ }^{7}$ : o Seminário de Prática de Pesquisa no Programa de Pós-

\footnotetext{
${ }^{6}$ A ementa, o programa, assim como metodologias de trabalho, referências bibliográficas e produções acadêmicas das estudantes podem ser acessados no site www.intelectuaisnegras.com

${ }^{7} \mathrm{O}$ Grupo Intelectuais Negras foi criado em 2014. Inicialmente como um espaço independente voltado a mulheres negras interessadas em discutir autoras feministas negras. Nesta primeira etapa, o grupo contou com a participação de diversas mulheres que foram fundamentais para sua continuidade. Entre as quais destaco e agradeço através do ato político de nomeá-las: Azoilda Loretto da Trindade (in
} 
Graduação em Educação da UFRJ, voltado para a formação de mestras com ênfase em epistemologias feministas negras; o projeto de extensão Intelectuais Negras Diálogos, que promove bimestralmente encontros abertos à comunidade para discutir a produção intelectual de mulheres negras. Além do citado curso eletivo, na pósgraduação, destacam-se as disciplinas: Educação, Gênero e Estudos Pós-coloniais e Ensino de História do Pós-Abolição e Feminismos Negros Interseccionais, oferecidas respectivamente no PPGE/UFRJ e no Programa de Pós-Graduação em Ensino de História (PROFHIST UFRJ). Todas essas ações inseridas em um projeto científico.

Ancorados nos aportes teórico-metodológicos de valores civilizatórios afrobrasileiros como ancestralidade, afetividade, corpo, ludicidade (TRINDADE, 2006), a presença do Grupo Intelectuais Negras na UFRJ gera uma infinidade de conteúdos sobre relações raciais e de gênero, importantes para estudo da história do tempo presente. Identificação, reconhecimento, empatia. Curiosidade, estranhamento, suspeição, diante de instigante paisagem. Uma sala de aula na zona sul do Rio de Janeiro protagonizada por jovens negras. Universitárias de diferentes estados, países e cantos da cidade que mesclando diários, poemas, lápis de cor e textos científicos vivenciam experiência de formação acadêmica singular. $O$ estudo semestral do pensamento de mulheres negras através de aulas em roda, com discussões de textos, confecção de desenhos e bordados, estímulo ao abraço, ao olhar, à escuta e à escrita criativa. Marcadas pela raridade e pelo distanciamento do padrão científico hegemônico, tanto a proponente ("minha primeira professora negra") quanto a estrutura de produção de conhecimento centrada nas premissas feministas negras são rotineiramente definidas por quem participa como "surreais".

memoriam); Claudielle Pavão, Célia Cristo, Janete Santos Ribeiro, Marta Muniz Bento, que compunham ao meu lado o núcleo gestor. Rapidamente, as propostas e objetivos foram transformando-se e os debates sobre as implicações e sentidos da manutenção de um grupo com objetivos acadêmicos fora da academia também se intensificaram. Em 2016, o grupo é institucionalizado na universidade, passando a se chamar Grupo de Estudos e Pesquisas Intelectuais Negras UFRJ. Para marcar essa ocasião realizamos o I Seminário Intelectuais Negras Escritas de Si, na Casa da Ciência. Situada no Campus da Praia Vermelha, na Urca, bairro carioca da zona sul, a repercussão do evento na comunidade acadêmica foi grande, evidenciando sentimentos de estranhamento e identificação diante do fato de mulheres negras contarem suas próprias histórias em um espaço historicamente fundamentado na lógica de objetificação da população negra pela qual a palavra "ciência" define-se. Encontra-se em fase de produção texto específico sobre a história de formação do GIN-UFRJ, que se insere no plano de desenvolvimento individual "Ciência das Mulheres Negras: pesquisa ativista e liderança acadêmica no Brasil", apoiado pelo Programa de Aceleração e Desenvolvimento de Lideranças Femininas Negras Marielle Franco Baobá - Fundo para Equidade Racial. 
A experiência de como professora universitária desenvolver práticas educativas cooperativas, que me permitem-me ensinar e aprender com meninas cheias de brilho e saberes variados - artes, literatura, audiovisual, alimentação, saúde, é potente. Uma potência da qual emerge uma nova comunidade científica. Protagonizada por intelectuais negras e fundamentada em concepções de ciência tecidas através das práticas de ler, escrever, interpretar e compartilhar histórias na sala de aula. Em acordo com bell hooks:

Para educar para a liberdade, portanto, temos que desafiar e mudar o modo como todos pensam sobre os processos pedagógicos. Isso vale especialmente para os alunos. Antes de tentarmos envolvê-los numa discussão de ideias dialéticas e recíprocas temos de lhes ensinar 0 processo (2013, p. 193).

\section{Intelectuais negras e ativismo científico: continuidades e inovações}

Considerando o papel político da nomeação nos feminismos negros, a materialização do Grupo Intelectuais Negras UFRJ também se relaciona a passos que vem de longe (WERNECK, 2019). ${ }^{8}$ Mais precisamente do final dos anos 1970 , quando mulheres negras iniciaram um brilhante e ousado movimento intelectual de cruzar discursos científicos e ativistas em seus trajetos profissionais.

Através da produção de monografias, teses, dissertações, eventos acadêmicos assim como da escrita e publicação de livros, cartilhas e materiais didáticos para os movimentos negros, essas ativistas acadêmicas que passo a nomear, entre muitas outras, protagonizaram diversificadas lutas intelectuais pela igualdade racial no Brasil: Azoilda Loretto da Trindade (13/09/2015), Beatriz Nascimento (12/07/1942-28/01/1995), Lélia Gonzales (01/02/1935-10/07/1994), Luiza Bairros (27/03/1953-12/07/2016). Sem dúvida, a escrita de seus trajetos científicos é um trabalho a ser feito. Dentro de uma história intelectual das mulheres negras, que ilumine a magnitude de suas realizações intelectuais. (PINTO; FREITAS, 2016; RIOS; ROSE, 2018).

\footnotetext{
${ }^{8}$ Alusão a "Nossos passos vêm de longe". Visibilizada na produção teórica da ativista e médica feminista negra Jurema Werneck, esta frase tornou-se um lema dos movimentos de mulheres negras, fincados no reconhecimento do papel da ancestralidade nas conquistas e lutas presentes.
} 
Em uma linha passado-presente de intelectuais negras, o conceito de movimento negro de base acadêmica (RATTS, 2009) é de grande contribuição ao meu trabalho. Voltado à análise da trajetória de sujeitos que na carreira universitária assumiram projetos políticos de afirmação racial, lidando com contradições entre individual e coletivo, acadêmico e ativista, a categoria estimula-me a examinar traços compartilhados e singulares que conectam minha história a dessas acadêmicas negras que abriram caminhos que seguem alimentados dentro de um contexto muito distinto.

Enquanto as intelectuais acima citadas trilharam caminhos acadêmicos como estudantes e professoras excepcionais, eu, três décadas depois, ainda que integre uma minoria docente e também seja racializada pelo discurso do brilhantismo, integro outro universo. Composto por uma significativa comunidade estudantil negra ${ }^{9}$, de maioria feminina, com a qual construo sentidos coletivos de negritude.

Um bom exemplo encontra-se na disciplina Intelectuais Negras. Para cursá-la, a Faculdade de Educação da UFRJ oferece semestralmente quarenta e cinco vagas. Dessas, a grande maioria é preenchida por estudantes negras, que em cinco anos de curso, considerando ouvintes, palestrantes e a categoria das visitantes ${ }^{10}$, beiram a casa de mil cursistas. Em média com dezoito e vinte e cinco anos, essas jovens chegam à universidade com novas demandas de conhecimento sobre empoderamento estético (\#meucrespoéderainha), financeiro (\#blackmoney), intelectual (\#leiaautorasnegras).

Grafadas com a linguagem das redes sociais, tais demandas influenciam diretamente a definição das agendas acadêmicas construídas coletivamente em sala e

\footnotetext{
${ }^{9}$ Pesquisa divulgada pelo IBGE registra que em 2018, 50,3\% dos estudantes de universidades públicas brasileiras são negros.

10 É recorrente a presença de mulheres negras não-matriculadas no curso por razões variadas: curiosidade, vontade de retomar os estudos "sem saber como", desejo de se reconciliar com o ambiente acadêmico após experiências traumáticas relacionadas ao racismo acadêmico, realizar o sonho de estudar ao lado de suas filhas. Sobre este último exemplo, o contrário também acontece. Mães universitárias acompanhadas por suas filhas, estudantes do ensino médio, que frequentam as aulas porque "gostaram da bibliografia", querem se preparar "melhor" para o ENEM, seguem feministas negras nas redes sociais, leram alguma autora negra e quiseram aprender mais. Além deste público amplo e diverso, também é comum a participação de convidadas - ativistas, artistas, escritoras, avós, tias, vizinhas, que ao contarem suas histórias promovem momentos de produção de conhecimento profundos para todas nós. De fato, este assunto merece texto específico, pois em muitos casos o compromisso e a seriedade das visitantes ultrapassa o das estudantes matriculadas, evidenciando o potencial de impacto extra-muros que a universidade possui se devidamente trabalhado.
} 
também em pesquisas individuais. ${ }^{11} \mathrm{O}$ que também contribuiu para caracterizar o projeto Intelectuais Negras UFRJ como uma política curricular de ação afirmativa. Que nascida dos diálogos entre academia, escola e movimentos sociais tem contribuído para suportar e expandir os avanços conquistados em termos de acesso das classes trabalhadoras ao ensino superior. ${ }^{12}$

\section{Dar a luz a nós mesmas: diferentes percepções acerca da intelectualidade de mulheres negras entre docentes, estudantes e trabalhadoras terceirizadas}

Visibilizar, na universidade, a mulher negra como sujeito intelectual e ao mesmo tempo criar discursos científicos que sustentem esta afirmação é desafiador, pois parte de dois movimentos que questionam, na prática, os pressupostos da subalternidade: a expressão da subjetividade feminina negra e a tomada do território da produção teórica, tradicionalmente associado ao masculino. Esse processo, pelo qual podemos perceber as assimetrias de gênero e raça, pode ser pensado dentro do que Petronilha Gonçalves (1998) conceitua dar à luz a nós mesmas. Em rituais de nascimento que envolvem segmentos da comunidade universitária distintos: professoras, estudantes, trabalhadoras terceirizadas. Sujeitos com demandas específicas que me desafiam a criar diálogos e linguagens variadas para fortalecimento do trabalho (COLLINS, 2012). Nesta seção, através da perspectiva do telling stories (WHITE, 2008), exponho experiências que contribuem observar os afetos relacionados ao dar à luz.

A primeira refere-se aos debates suscitados pela proposição da disciplina Intelectuais Negras, levada, em março de 2015, à reunião de colegiado do Departamento de Didática da Faculdade de Educação da UFRJ, com a seguinte ementa:

\footnotetext{
${ }^{11}$ Meu último livro Você pode substituir Mulheres Negras como objeto de estudo por Mulheres Negras contando sua própria história, que combina métodos como narrativa na primeira pessoa, contação de histórias e análises de fontes primárias para interpretar a história do Brasil, insere-se nesse contexto.

12 A escrita deste texto ocorre em um contexto no qual as atividades acadêmicas presenciais encontramse suspensas na UFRJ. Diante dessa situação extrema e da importância da manutenção de vínculos entre professora e estudantes, organizei com a turma encontros de acolhimento. Nesses espaços virtuais, conversamos sobre as experiências da quarentena articulando-as às demandas de conhecimento sobre a intelectualidade de mulheres negras. Inspiradas por discussões como as presentes no texto "Vivendo de amor" de bell hooks, nesses espaços refletimos bastante sobre subjetividades políticas negras no Brasil contemporâneo.
} 
Conhecimentos orais e escritos de mulheres negras. Histórias, práticas e nuances dos feminismos negros (cis e transgêneros) e seus sujeitos no Brasil, na América Latina e no continente africano. Práticas educativas emancipatórias, relações de gênero e antirracismo. Pensamento feminista negro e reeducação das relações étnico-raciais em contextos escolares. Pesquisa ativista e a construção de narrativas na primeira pessoa ("escritas de si"). Diálogos horizontais entre produção escolar, acadêmica e militante. As relações entre subjetividade (saberes localizados) e conhecimento científico. $O$ trabalho com gêneros literários diferenciados em sala de aula (livros e artigos, entrevistas, romances, poesias, letras de música, documentários). Os conceitos de intelectual negra e interseccionalidade.

Findadas a apresentação da proposta, a leitura do parecer favorável e a votação, entre elogios e palmas, destaca-se o pedido à palavra de um colega. Dirigindo-se à frente do plenário, o docente parabeniza a iniciativa. Todavia, assinala a inadequação curricular da proposta. Ao seu ver, mais "alinhada a um curso de extensão", que evitaria a colocação do "currículo em muitas caixinhas". O pronunciamento é acompanhado por uma segunda colega que "desabafa" seu "receio" sobre a "inexistência de bibliografia para o curso". Essas falas, arrematadas pela pergunta recorrente - "Mas por que intelectuais negras e não só intelectuais?" Caracterizadas como insulto ao trabalho intelectual (WHITE, p. 21), esses posicionamentos expressam os usos seletivos dos discursos de neutralidade e distanciamento.

Em se tratando da comunidade estudantil, existem muitas demandas dos movimentos sociais levadas para salas de aula, grupos de pesquisa e demais espaços universitários. Essa entrada de demandas é essencial, pois ela se pauta no diálogo entre academia e sociedade, no entanto, existe todo um caminho para que tais demandas sejam lapidadas como conhecimentos científicos. No trabalho com epistemologias alternativas dos feminismos negros tenho aprendido sobre a importância de criar estratégias formativas diferenciadas. Que estimulem estudantes a conquistarem autonomia intelectual para se apropriarem dos códigos da cultura acadêmica hegemônica. Um investimento intelectual indispensável para instrumentalizar novas gerações para produção de conhecimento científico.

Nesse processo formativo, é comum que as primeiras versões de textos monográficos e exames de qualificação cheguem na forma de narrativas de ativismo pessoal. Ou seja, textos repletos de expressões como "Eu, mulher negra resisto", 
"Jovem Negro Vivo", "Mulheres Negras Movem o Mundo" que evidenciam que o trabalho de formação acadêmica está só começando. Evidenciam também que o desafio para sustentar a tradição feminista negra de articular pensar e fazer é grande. Isso porque tais articulações não são ensinadas na universidade. Lembro, nesse caso, que um dos argumentos principais de estudantes que participam das ações que promovemos é o do desejo de aprender a articular teoria e prática.

Nesse contexto, no Grupo Intelectuais Negras, articulo conceitos e metodologias científicas com aquelas aprendidas em movimentos sociais, tais quais diários de bordo, rodas de conversa, vivências corporais, entre outras. Essa articulação estimula uma autoria acadêmica mais livre e criativa, por meio da qual invento métodos como o da narrativa na primeira pessoa. Compartilhados no início das reuniões, estes escritos, nos quais a única obrigação é se esforçar para conectar as ideias pessoais àquelas lidas, trazem ricas interpretações sobre textos de autoras negras que integram os programas de curso. E, não menos importante, contribui para aliviar traumas gerados pelo elitismo acadêmico e expressos em discursos anti-cotas nas aulas, em correções de prova que invalidam ideias e uma série de outras situações de assédio acadêmico, fundamentadas na cultura do aqui não é paravocê.

As leituras em voz alta desses materiais constituem-se em momentos de muita emoção nos quais percebemos a potência das conexões entre subjetividade e objetividade. Dada a força das histórias evocadas, observa-se que o texto da aula espontaneamente mistura-se ao texto da vida. Marcado por descobertas e ressignificações da negritude, da infância, de histórias de amor, trabalho, família. Compartilhado entre abraços, lágrimas e feridas, este movimento intelectual das estudantes tem sido fundamental para aprimorar meu trabalho científico, identificando dentro de vínculos acadêmicos de afeto e cumplicidade, que conhecimentos sistematizar na história intelectual de mulheres negras.

Na perspectiva da comunidade de aprendizado (hooks, 2013), eles também me possibilitam, como professora e orientadora, ensinar estudantes negras que confiam em mim e se espelham no meu trabalho, a desenvolverem suas próprias estratégias de curadoria do conhecimento de mulheres negras. Tratado pelo mainstream como não acadêmico, muito pessoal, militante. Considerando a lida cotidiana com estas 
invalidações, costumo provocá-las com a mesma indagação que me faço e busco responder: "Como você acha que seu texto pode ser trabalhado para produzir uma linguagem acadêmica que em vez de te expor e fragilizar constitua-se em uma nova forma de fazer ciência?"

E assim, juntas aprendemos que, independente das respostas, que serão variadas, todas precisaremos construí-las dentro de padrões científicos que articulem subjetividade, objetividade, rigor teórico e ativismo como modelo de produção de conhecimento possível. ${ }^{13}$

Ainda em relação às interações no espaço acadêmico, último e importantíssimo exemplo encontra-se nas relações de aprendizado e identificação que professora e estudantes estabelecemos com as trabalhadoras terceirizadas. Usualmente invisibilizadas no espaço acadêmico como tias da limpeza, essas profissionais conduzem conosco diferentes processos de produção de conhecimentos. Contação de histórias pessoais, de filhas e netas interessadas no estudo. Participação nas aulas com depoimentos sobre suas trajetórias, seguidos de palmas e abraços de reconhecimentos. Compartilhamento de conhecimentos gastronômicos mesclados a ricas análises da conjuntura política.

Em diálogo com Patricia Hill Collins, essas e muitas outras histórias dizem respeito a importantes fundamentos do pensamento de mulheres negras: a experiência como critério de significado e a prática da "autodefinição" e "autoavaliação":

Autodefinição envolve desafiar 0 processo de validação do conhecimento político que resultou em imagens estereotipadas externamente definidas da condição feminina afro-americana. Em contrapartida, a autoavaliação enfatiza o conteúdo específico das autodefinições das mulheres negras, substituindo imagens externamente definidas com imagens autênticas de mulheres negras (COLLINS, 2016, p. 102).

O trabalho de formação acadêmica com esses e outros conceitos feministas negros contribui para estimular jovens a produzirem novos modelos interpretativos nos

\footnotetext{
${ }^{13}$ Meu credenciamento nos dois programas de pós-graduação em que atuo ocorreram entre 2016 e 2017. Nesse tempo, eu aprendi muito com Anne Carolinne Carvalho Nunes, Daiana da Silva, Evelyn Beatriz Lucena Machado, Pâmela Cristina Nunes de Carvalho e Sylvia Soares Souza, sobre o trabalho com epistemologias feministas negras. Todas elas, a quem agradeço imensamente, tornaram-se mestras e seguem atuando na educação básica pública e privada com muito compromisso e talento.
} 
quais mães, tias, avós, vizinhas são reposicionadas como autoras, leitoras, protagonistas da história intelectual de mulheres negras.

Depois que a conheci aqui no curso, todas as noites leio Conceição Evaristo para minha avó iletrada, contou-nos a estudante da Escola de Belas Artes.

Eu deixei de ser intelectual negra para que você fosse, rememora a universitária do curso de Comunicação Social, a fala de sua mãe, trabalhadora doméstica, quando a jovem pensou em desistir da faculdade.

$\mathrm{Na}$ próxima seção, esboço alguns desafios postos à produção científica na primeira pessoa. Se em países como Inglaterra, EUA, Índia, este debate encontra-se bastante avançado, no Brasil, ele está só começando (HARDING, 1988).

\section{Professora, eu posso escrever na primeira pessoa? o desafio de transformar reivindicações em novos conhecimentos científicos}

Um dos principais mecanismos de produção intelectual de mulheres negras é o contar histórias. Conduzida em cozinhas, quintais de casas, transportes públicos, esta tradição de narrar na primeira pessoa tem propiciado por séculos a produção de conhecimentos sobre educação, família, ativismo. Ao mesmo tempo que primordial nas classes trabalhadoras, a narrativa na primeira pessoa costuma ser recebida com muita desconfiança no mainstream:

Professora, como escrever na primeira pessoa sem ser deslegitimada na academia?

Minha avó entregou-me uma caixa antiga de fotografias com nossas imagens. Posso escrever a história de minha família na monografia com este material?

Descobri uma biblioteca organizada e financiada por um grupo de mulheres negras em um bairro de Nova Iguaçu. Este pode ser o tema do meu mestrado?

Posso trazer para a pesquisa os projetos que desenvolvo com meus pequenos na educação infantil?

Professora, eu posso escrever texto acadêmico na primeira pessoa?" 
Recorrentes no pensamento de estudantes negras, essas indagações mostram que a entrada das classes trabalhadoras na academia culminou na elaboração de novas perguntas e formas de se relacionar com a ciência. Pautadas nas premissas de mulheres negras, as perguntas ajudam a pensar tanto na potência de novas ideias quanto nos desafios à sua validação científica. Como afirma Collins: "os métodos usados para validar reivindicações de conhecimento também devem ser aceitáveis para o grupo que controla o processo de validação de conhecimento" (p. 407) Ainda discutidos superficialmente no Brasil, esses são temas fundamentais para construção de epistemologias alternativas que fundamentem escrita de si de intelectuais negras como uma alternativa científica (XAVIER, 2015).

No Grupo Intelectuais Negras UFRJ, o trabalho para transformar reivindicações em conhecimentos tem se mostrado muito necessário, inspirador, frutífero. Nos termos da criação de uma perspectiva negra que se define através de negociações entre os meus pontos de vista de pesquisadora, as reivindicações das novas gerações e os métodos hegemônicos de validação. Um trabalho de produção de novas abordagens de história social focadas nas mulheres negras para muitas vidas.

R: Sim, você pode e deve escrever na primeira pessoa. Faça isso consciente de que falar cientificamente por nós mesmas é uma invenção que demanda tempo, paciência, habilidade para criar estratégias e ferramentas próprias. \#nossospassosvêmdelonge.

\section{Referências}

CARVALHO, P.C. N. de. 'Pisa na matamba': epistemologia jongueira e reeducação das relações raciais. 2020. 142f. Dissertação (Mestrado em Educação) - Programa de Pós-Graduação em Educação da UFRJ, Rio de Janeiro.

COLLINS, P. H. Pensamento feminista negro: conhecimento, consciência e a política do empoderamento. São Paulo: Boitempo, 2019.

Aprendendo com a outsider wihin: a significação sociológica do pensamento feminista negro. Revista Sociedade e Estado, v. 31, n.1, p. 99-127, jan./abr. 2016. Disponível em: https://www.scielo.br/pdf/se/v31n1/0102-6992-se-31-0100099.pdf Acesso em: 14 jun. 2020. 
. On Intellectual Activism. Filadelfia: Temple University Press:2012.

EVARISTO, C. Insubmissas lágrimas de mulheres negras. Belo Horizonte: Nandyala, 2011.

FERREIRA, L. Menos de 3\% entre docentes da pós-graduação, doutoras negras desafiam racismo na academia. Gênero \& Número, Rio de Janeiro, 20 jun. 2018.

GRUPO DE ESTUDOS E PESQUISAS INTELECTUAIS NEGRAS UFRJ. https://www.intelectuaisnegras.com

HOOKS, B. Ensinando a transgredir: a educação como prática da liberdade. São Paulo: Martins Fontes, 2013.

IBGE. Desigualdades sociais por cor ou raça no Brasil. In: studos e Pes uisas nfo ma o emog fica e ocioecon mica n.41, p. 1-12, 2019. Disponível em:

https://biblioteca.ibge.gov.br/visualizacao/livros/liv101681_informativo.pdf Acesso: 14 jun. 2020.

LADNER, J. Tomorrow's Tomorrow: The Black Woman. Garden City, N.Y.: Doubleday, 1971.

MACHADO, E B L. Mulheres negras e o ensino de História da escravidão. 2018. 122f. Dissertação (Mestrado em História) - Programa de Pós- Graduação em Ensino de História da UFRJ, Rio de Janeiro, 2018.

MATTOS, A; XAVIER, G. Activist Research and The Production of non- hegemonic knowledges: Challenges for Interseccional Feminism. In: Feminist Theory, v. 17, n. 2, p. 239-245, ago. 2016. Disponível em: http://fty.sagepub.com/content/17/2/239.full.pdf?ijkey=rJuYlzPVek5QH09\&keytype=finite Acesso: 16 jul. 2016.

NUNES, A C C. Como contar histórias que não são minhas? 0 protagonismo das meninas negras na escola privada. 2020. 145f. Dissertação (Mestrado em Educação) - Programa de Pós-Graduação em Educação da UFRJ, Rio de Janeiro, 2020.

PA MA , P. Feminismo negro: la política como articulación. In: JABA DO, Mercedes (ed.). Feminismos Negros: Una Antología. Traficantes de Sueños: Madrid, 2012, p. 245-267. Disponível em

https://www.traficantes.net/sites/default/files/pdfs/Feminismos\%20negros-TdS.pdf Acesso em: 30 jan. 2018.

PINTO, A F M; FREITAS, F da S. L B: uma "bem lembrada entre nós". In: Afro-Ásia, v. 55, p. 215-276, 2017. Disponível em: http://dx.doi.org/10.9771/aa.v0i55.24316. Acesso: 14 jun. 2020. 
RATTS, A. Eu sou atlântica: sobre a trajetória de vida de Beatriz Nascimento. São Paulo: Instituto Kwanza; Imprensa Oficial, 2005. Disponível em: http://www.imprensaoficial.com.br/downloads/pdf/projetossociais/eusouatlantica.pdf?fbcl id=IwAR0v3Q55v1X2ygXsfRK6vjfYweOMmM1ZTDwMBFTuw74OKMRb39VxMf9uANg Acesso em: 14 jun. 2020.

- Encruzilhadas por todo percurso: individualidade e coletividade no movimento negro de base acadêmica. In: PEREIRA, Amauri Mendes; SILVA, Joselina da. (Org.). ovimento eg o asi ei o: esc itos sob e os sentidos de democ acia e usti a socia no asi . Belo Horizonte-MG: Nand ala Livros e Serviços Ltda, 00 , v. 1 , p. 81-108. Disponível em: https://www.geledes.org.br/wpcontent/uploads/2016/01/Encruzilhadas_por_todo_percurso_individu.pdf Acesso em: 14 jun. 2020.

2010.

; RIOS, Flávia. Lélia Gonzalez. São Paulo: Summus; Selo Negro,

ROSE, G. Azoilda Loretto da Trindade: um caminho rumo à construção existencial das identidades existenciais negras. 2020. Dissertação (Mestrado em Reeducação das Relações étnico-raciais) - Programa de Pós-Graduação em Reeducação das Relações Étnico-Raciais, CEFET, Rio de Janeiro, (pesquisa em andamento).

SANTANA, B. A escrita de si de mulheres negras: memória e resistência ao racismo. 2020. 287f. Tese (Doutorado em Ciências da Informação) - Programa de PósGraduação em Ciência da Informação da Escola de Comunicações e Artes da Universidade de São Paulo, São Paulo.

SILVA, D da. Professoras negras: autoria e protagonismo na construção de práticas educativas antirracistas e decoloniais na educação infantil. 2020. 140f. Dissertação (Mestrado em Educação) - Programa de Pós-Graduação em Educação da UFRJ, Rio de Janeiro.

SILVA, J da. Doutoras professoras negras: o que nos dizem os indicadores sociais. In: Perspectiva, Florianópolis, v. 28, n. 1, p. 19-36, jan./jun. 2010. Disponível em: https://doi.org/10.5007/2175-795X.2010v28n1p19 Acesso em: 14 jun. 2020.

SILVA, P B G. Chegou a hora de darmos à luz a nós mesmas: situando-nos enquanto mulheres negras. In: Cad. Cedes, v.19, n. 45, p.7-23, 1998. Disponível em:

https://www.scielo.br/scielo.php?pid=S0101-

$32621998000200002 \&$ script=sci_abstract\&tIng=pt. Acesso em: 14 jun. 2020.

SOUZA, S de. Abioye, Bruna e Cora: uma proposta de reeducação das relações raciais na literatura infantil. 2019. 170f. Dissertação (Mestrado em Educação) Programa de Pós-Graduação em Educação da UFRJ, Rio de Janeiro, 2019. 
TRINDADE, A L da. Fragmentos de um discurso sobre afetividade. In: Brandão, Ana Paula. Saberes e fazeres: modos de ver. Rio de Janeiro: Fundação Roberto Marinho, 2006 (Cadernos A Cor da Cultura). Disponível em: http://www.acordacultura.org.br/sites/default/files/kit/Caderno1_ModosDeVer.pdf Acesso em: 09 mar. 2015.

WERNECK, J. Nossos passos vêm de longe! Movimentos de mulheres negras e estratégias políticas contra o sexismo e o racismo. In: Vents d'Est, vents d'Ouest: Mouvements de femmes et féminismes anticoloniaux [en línea]. Genève: Graduate Institute Publications, 2009. Disponível em: <http://books.openedition.org/iheid/6316>. ISBN: 9782940503827. DOI: 10.4000/books.iheid.6316 Acesso em: 14 jun. 2020.

WHITE, D G. Telling Stories: Black Women Historians in the Ivory Tower. The University of North Carolina Press, 2008.

UNIVERSIDADE FEDERAL DO RIO DE JANEIRO. Intelectuais Negras: escritas de si, saberes transgressores e práticas educativas de mulheres negras. Ementa da disciplina eletiva inscrita sob o código EDW na grade curricular da Faculdade de Educação da UFRJ, 2015.

XAVIER, G. Você pode substituir Mulheres Negras como objeto de estudo por Mulheres Negras contando sua própria história. Rio de Janeiro: Malê, 2019.

Brancas de almas negras? Beleza, racialização e cosmética na imprensa negra pós-emancipação (EUA, 1890-1930). 2012. 297f. Tese. (Doutorado em História Social da Cultura) - Programa de Pós-Graduação em História Social da Universidade Estadual de Campinas, Campinas, 2012.

Ciência de mulheres negras: liderança acadêmica e pesquisa ativista no Brasil. Plano de Desenvolvimento Individual apoiado pelo Programa de Aceleração e Desenvolvimento de Lideranças Femininas Negras Marielle Franco do Baobá - Fundo para Equidade Racial, 2020.

Por que só $0,4 \%$ das professoras doutoras da pós-graduação do

Brasil são negras? In: Nexo Jornal, 25 jun. 2018. Disponível em: https://www.nexojornal.com.br/colunistas/2018/Por-que-só-04-das-professorasdoutoras-na-pós-graduação-do-Brasil-são-negras Acesso: 14 jun. 2020.

Como você quer contar sua história? Texto apresentado no lançamento do livro Você pode substituir Mulheres Negras como objeto de estudo por Mulheres Negras contando sua própria história na XVII Festa Literária Internacional de Paraty 2019. 